\title{
SEPARATA
}

\section{AVALIAÇÃO DO DESEMPENHO DOCENTE O QUE MEXE COM OS PROFESSORES}

Formação de Professores

Supervisão Pedagógica

Avaliação do Desempenho Docente

Observação de Aulas

Desenvolvimento profissional dos professores

\author{
Coordenador \\ José Afonso Baptista*
}

Autoras

Maria Martins

Paula Arnaud

Sandra Soares

Deolinda Silva

\footnotetext{
* Professor na Universidade Católica, onde se doutorou em Ciências da Educação. Coordena cursos de doutoramento e de mestrado nesta área. Foi metodólogo, orientador pedagógico e coordenador dos estágios da UCP-Viseu. Foi ainda consultor da UNICEF para a Educação e Diretor Regional de Educação do Centro.
} 



\section{APRESENTAÇÃO}

\section{A problemática}

Os textos que aqui se editam foram concebidos e escritos no âmbito do mestrado em Ciências da Educação ${ }^{\dagger}$, especialidade de Supervisão Pedagógica e Avaliação de Docentes, mais especificamente no âmbito da unidade curricular Teorias e Modelos de Supervisão Pedagógica. Esta é a temática dominante, que se alarga inevitavelmente aos conteúdos de outras unidades curriculares, mas com uma dívida muito especial à Observação de Aulas e Práticas Educativas e às Teorias e Modelos de Avaliação do Desempenho ${ }^{\ddagger}$. Supervisão pedagógica (SP), avaliação do desempenho docente (ADD) e observação de aulas (OE) delimitam os horizontes deste trabalho.

As autoras têm vários pontos em comum. Para além de serem alunas deste mestrado, o facto de terem também o grau de mestre em Administração e Organização Escolar e de terem concluído a componente curricular do mestrado em Supervisão Pedagógica e Avaliação de Docentes, refira-se o facto não menos importante de terem vivido nas respetivas escolas o processo de avaliação do desempenho docente, quer como avaliadas, quer como avaliadoras, o que lhes confere uma autoridade singular nesta área de estudo. Ao aprofundamento de dois campos teóricos inseparáveis, acrescentam a experiência e as práticas na escola, caldeadas por uma indispensável experiência de investigação científica.

Neste campo de análise ganha especial relevo a ADD, nem sempre pelas melhores razões. De facto, foram as políticas educativas dos últimos anos que colocaram a ADD na (des) ordem do dia. Não está em causa saber se deve ou não haver avaliação dos professores. A avaliação faz parte de qualquer programa de formação ou desenvolvimento, enquanto estratégia de análise, reflexão e melhoria. $\mathrm{O}$ problema está no facto de se eleger e privilegiar a avaliação como instrumento do controlo remoto do sistema educativo e seus atores, reduzindo a importância da supervisão pedagógica, formativa e reflexiva, como forma de garantir a qualidade do serviço educativo.

O que está em causa na análise dos modelos teóricos da ADD é o problema da complementaridade ou da inconciliabilidade entre uma dimensão formativa, que visa o desenvolvimento profissional, e uma dimensão sumativa e classificatória, que controla e subjuga. Trata-se de saber se a supervisão e a ADD elegem como objetivo prioritário a emancipação e autonomia dos professores ou se se limitam a funções meramente administrativas de controlo docente. Queremos professores autónomos,

\footnotetext{
${ }^{\dagger}$ Universidade Católica Portuguesa, Centro Regional das Beiras, ano de 2011-2012.

* Merecem referência especial os docentes destas UC's, respetivamente, José Afonso Baptista, Célia Ribeiro e Vítor Alaíz, sem omitir os docentes de outras unidades: Paulo Pereira, Nuno Melão e Paulo Ribeiro. A todos o nosso reconhecimento pela colaboração direta ou indireta neste trabalho.
} 
reflexivos e conscientes, ou queremos professores autómatos, que se limitam a reproduzir os comportamentos e atitudes pré-definidas em grelhas classificatórias?

A ADD não pode ser percebida como uma ameaça, mas antes como um desafio. A dimensão transformadora e emancipatória vivida e partilhada no interior da escola deverá sobrepor-se à burocracia normalizadora imposta pela tutela. A conflitualidade vivida entre docentes comprometeu o clima de escola e pôs em causa a confiança necessária entre os seus atores, com particular incidência nas relações entre avaliadores e avaliados. Em vez de unir e mobilizar os professores, a ADD foi sentida como uma agressão ao seu profissionalismo e uma ameaça ao seu prestígio.

Este é o campo teórico que se analisa e aprofunda nos textos que seguem, com base na literatura especializada e na legislação em vigor.

\section{Questões de investigação e dados de observação}

Aos quadros teóricos apresentados na revisão da literatura seguem-se narrativas sobre experiências vividas pelas próprias autoras, depoimentos e informações recolhidos junto dos intervenientes no processo de ADD e dados de observação do maior interesse. A informação recolhida reporta-se às escolas onde as próprias autoras viveram o processo de ADD, quer como avaliadas, quer como avaliadoras. A entrevista, a observação direta e a análise de grelhas e de outros materiais são os instrumentos para a recolha da informação.

Temos assim três referentes em confronto: o referencial teórico fornecido pela revisão da literatura, o quadro legislativo que regulamenta a ADD e as práticas vividas e observadas nas escolas. Trata-se de investigar de que modo os atores interpretam o quadro teórico e o quadro legislativo, de que modo as práticas refletem ou ignoram esses quadros e que efeitos, positivos ou negativos, produzem na melhoria da ação educativa. No essencial, trata-se de responder às seguintes questões:

- Os processos de ADD seguiram fielmente os quadros teóricos e os normativos em vigor?

- A observação de aulas seguiu um modelo de supervisão escolar reflexivo e integrado num projeto de crescimento profissional ou limitou-se a um mero ato administrativo, burocrático e de avaliação sumativa para a progressão na carreira?

- Os avaliadores foram de facto agentes do desenvolvimento dos avaliados ou foram apenas classificadores?

- Foi possível conciliar a dimensão formativa e de desenvolvimento profissional com a dimensão classificatória? 
- As grelhas de observação utilizadas refletem uma orientação formativa ou não passam de meras listas de verificação de apoio à avaliação sumativa?

- Houve conflitos e turbulência nas escolas gerados pelo processo de ADD?

- Houve ou não contestação generalizada ao modelo de ADD implementado?

- Haverá outros problemas, - sociais, políticos, éticos, relacionais -, associados a este modelo de ADD?

Os depoimentos e informações recolhidos mostram que a supervisão, a avaliação do desempenho e a observação de aulas não se desenvolveram de acordo com os referenciais teóricos. A lógica burocrática e classificatória sobrepôs-se à dimensão reflexiva, dialogada, participada, que conduz à análise e consciência das necessidades do desenvolvimento profissional, à ação conjunta para a melhoria da organização escola e da ação educativa.

As orientações definidas foram sempre no sentido de atribuição de uma classificação numérica e os avaliadores foram em geral apenas classificadores, sem qualquer preocupação de fornecer aos professores o feedback construtivo sobre o seu desempenho. Os princípios em que assenta o processo de ADD e uma supervisão transformadora foram subvertidos.

As escolas não foram sensíveis nem às necessidades de crescimento profissional dos docentes nem do desenvolvimento organizacional que conduz à mudança da escola para a melhoria. Nem as lideranças nem os docentes em geral reconheceram valor acrescentado ao processo de ADD. O seu valor formativo passou à margem e foi ignorada qualquer necessidade ou qualquer iniciativa orientada para a melhoria da organização das escolas.

Faltou comunicação e diálogo nos processos de ADD a todos os níveis, com incidência na relação avaliador/avaliado que, ao invés de uma relação interpares, refletiu a verticalidade hierárquica do poder e da subjugação. Faltou uma visão democrática da supervisão, pautada pelo debate de ideias e pontos de vista, pela reflexão partilhada e pela aprendizagem horizontal.

Faltou espaço aos professores especializados, quer onde não existiam, quer onde existiam e não foram reconhecidos. $O$ exercício de cargos especializados não deve ficar ao arbítrio de docentes e mesmo de lideranças sem formação.

\section{Sugestões}

Todos os trabalhos referem de forma explícita ou implícita a necessidade de envolvimento e maior responsabilidade dos professores com formação especializada. Qualquer mudança implica sempre mobilizar e formar e é errado pensar que os professores estão sempre preparados para novas funções e responsabilidades. Esse é o erro frequente das reformas top-down que 
esbarram quase sempre com a indiferença, a oposição ou mesmo a revolta dos professores.

É preciso assegurar que a ADD se desenvolva num processo permanente de comunicação e de diálogo no interior da escola, com particular responsabilidade para as lideranças de topo e intermédias, mas promovendo igualmente uma relação estreita e paritária entre avaliador e avaliado, evitando cair numa relação hierárquica e burocrática que inviabiliza a confiança e a construção de um percurso em comum. Trata-se de um processo de interação permanente, potenciando a dimensão formativa e reflexiva da avaliação.

É importante perceber, pelo menos ao nível da escola, que o grande objetivo da supervisão e da ADD é o desenvolvimento profissional dos professores, a sua valorização e envolvimento nas tarefas comuns, na análise e reflexão partilhada dos problemas e da sua superação. Mas não se trata apenas de formar e integrar os novos professores. O que está em causa é também o desenvolvimento global da organização escola e a qualidade do serviço que presta. Deve ser este o sentido da formação em contexto de trabalho, tanto quanto possível em processos de investigação-ação.

A ADD é um processo complexo e faseado. Nunca terá sentido se for reduzido a um simples momento de observação de aulas traduzido numa classificação. A literatura da especialidade fornece modelos claros e simples para a organização da ADD como um processo continuado e sistemático e como estratégia necessária à melhoria da escola. Para isso é importante a mobilização e organização de equipas de professores especializados que possam acompanhar a avaliação de desempenho docente dentro do espírito de uma cultura de cooperação orientada para a melhoria permanente.

As grelhas de observação são importantes instrumentos de orientação e registo de dados. Mas seria desejável cruzar com outros modelos de instrumentos, porventura mais descritivos e interpretativos, mais abertos, menos redutores e adaptados aos contextos de trabalho e formação.

\section{Conclusões: há mais em jogo}

A questão da ADD não é científica nem técnica, é política. A literatura da especialidade é hoje abundante na apresentação dos caminhos a seguir. O problema está mais uma vez na estratégia imposta por uma administração centralista, normalizadora e uniformizadora. O ministério continua a ser o ator principal, muitas vezes único, no lançamento de uma política de objetivos perversos. $\mathrm{O}$ essencial da ADD ou não chega às escolas ou chega de forma distorcida, transformando-se num acréscimo de burocracia o que poderia ser um poderoso instrumento de melhoria da qualidade da educação. Mais uma vez, o ministério continua a fazer o que deveria ser feito nas escolas: o trabalho de organização, de formação, de envolvimento e crescimento profissional é uma competência das escolas e é aí que deve ser concebido e levado à prática. O que está em causa mais uma vez é a autonomia da escola e a sua responsabilidade para recrutar os professores de que precisa, para os formar à medida das necessidades e para implementar as 
políticas e os programas de melhoria da qualidade da educação. Os professores estão ao serviço das escolas e das comunidades que servem e não ao serviço do ministério da educação.

A formação de professores é um desafio permanente de resposta aos novos problemas das escolas e das comunidades. Formação científica e formação especializada. Hoje não faltam nem professores nem candidatos a professores. Mas falta uma política de formação democrática, acessível a todos, mormente para o exercício de cargos e funções específicos. De facto, a formação especializada só está ao alcance dos que a podem pagar e o seu custo impede o acesso à maioria dos professores. Com a diminuição drástica do número de alunos nas licenciaturas e mestrados em ensino, as universidades têm hoje recursos para um investimento em força nos

professores. É mais uma vez uma questão política e de má política. Investir na formação especializada dos professores permitiria poupar em cada ano os milhões absorvidos pelas turmas de repetentes e evitar que muitos milhares de alunos deixem a escola sem formação e sem diploma. Outros países investem na prevenção o que gastamos no desperdício.

Com a publicação deste trabalho pretendemos mostrar o que é preciso fazer e como se pode fazer. Quando as reformas e mudanças top-down falham sistematicamente, é preciso encontrar alternativas para resolver os problemas. Importa preparar os professores para a mudança no interior e a partir das escolas e das comunidades educativas. É neste processo que as universidades têm uma palavra a dizer. Mais uma vez é preciso deslocar a formação das instâncias administrativas e burocráticas para as instâncias científicas e de formação.

\section{Apresentação dos trabalhos}

\section{Maria Martins, "Supervisão e Desenvolvimento Profissional em Contexto de ADD. Olhar crítico sobre o processo avaliativo de 2009/2011 na Escola Alfa".}

Analisa a problemática da ADD com base na literatura da especialidade e na produção normativa em Portugal, centrando-se nos modelos teóricos que procuram conciliar uma dimensão formativa e desenvolvimentista e uma outra de caráter sumativo, com objetivos de diferenciação. Reconhecendo que a ADD se revela essencial para a melhoria dos sistemas educativos, mostra que a turbulência e conflitos que gera em ambiente escolar afetam as dinâmicas da escola e comprometem o bom relacionamento entre os professores. O que está em causa é o choque entre dois modelos de avaliação, um mais formal e sumativo orientado para a seleção, outro centrado no desenvolvimento pessoal e profissional dos professores, condição necessária para a melhoria da qualidade do ensino e das aprendizagens.

Ao desenvolvimento teórico desta problemática, a autora acrescenta duas dimensões não menos importantes, que decorrem da própria vivência e sensibilidade como docente envolvida neste processo e da auscultação, através de entrevistas, de três docentes avaliadores numa escola da região 
centro no período de 2009/2011. A observação e análise das práticas revelam a sua dissonância com os modelos teóricos propostos pela literatura da especialidade, com os normativos e com o próprio projeto educativo. Os entrevistados consideram que os professores avaliadores foram apenas classificadores. O processo formativo e o desenvolvimento pessoal e profissional ficaram à margem.

Para a autora, grande parte dos constrangimentos referidos, deve-se à falta de formação dos supervisores.

\section{Paula Arnaud, "Observação de aulas em contexto de ADD: função classificatória ou emancipatória da classe docente?"}

Elegendo a mesma temática, mas pondo em relevo a problemática da observação de aulas no contexto da avaliação dos professores, a autora procurou observar e analisar de que forma o processo foi implementado e "vivido" em duas escolas onde exerceu a função de avaliadora e avaliada, analisou as grelhas de observação de aulas e ouviu os docentes sobre o impacto que a observação de aulas teve no seu crescimento profissional e no desenvolvimento da organização educativa no seu todo.

Paula Arnaud considera a observação de aulas uma ferramenta poderosíssima para a melhoria da qualidade do ensino e para a mudança na escola, no contexto mais amplo da supervisão pedagógica orientada para a melhoria da prática docente. O que está em causa é a reflexão sobre a ação assente no caráter formativo da avaliação. A autora defende que a observação de aulas deverá ser implementada segundo um modelo reflexivo que não se esgote em si mesmo mas inserido num projeto de avaliação global da escola. O objetivo da supervisão e da ADD é o desenvolvimento qualitativo da organização escola e dos seus docentes.

A componente empírica teve como objeto o estudo de duas escolas onde a autora exerceu a função de avaliadora e avaliada e procurou auscultar as opiniões e "estados de alma" de outros avaliadores e avaliados relativamente ao impacto que a observação de aulas teve no seu desenvolvimento/crescimento profissional e da organização educativa no seu todo. O que estava em causa era saber se o processo de observação de aulas foi monitorizado segundo um modelo de supervisão reflexivo e integrado num projeto de escola ou se apenas se limitou a um mero ato administrativo, burocrático e de avaliação sumativa.

Concluiu que a função dominante foi a classificatória e que nas Escolas A e B as lideranças e comunidade docente em geral não reconheceram nem vantagens nem valor acrescentado no que respeita a valorização e melhoria da organização escolar e às práticas pedagógicas e desenvolvimento profissional dos docentes. Foi um processo gerador de conflitos e o professor observado teve um papel passivo, sendo a observação de aulas (duas) um ato isolado de avaliação sumativa determinante para a avaliação do professor, numa dimensão meramente sumativa, estandardizada e punitiva. 


\section{Sandra Alves Soares, "Avaliação de Desempenho Docente e Supervisão Pedagógica: Veneno e Antídoto no mesmo pacote?"}

Sandra Soares apresenta igualmente um quadro teórico e um caso real de observação de aulas em que equaciona a possibilidade de conciliação ou a incompatibilidade entre duas modalidades de avaliação. Chamando a atenção para as finalidades da ADD, - avaliação para o desenvolvimento e/ou avaliação para o controlo -, salienta que, em vez de estar ao serviço da melhoria e da qualidade do ensino e das aprendizagens, a avaliação esgota-se em procedimentos puramente burocráticos.

Defendendo que a supervisão pedagógica e a ADD deveriam estar ao serviço da requalificação dos profissionais da educação, do seu crescimento e desenvolvimento profissional, estimulando o perfil do professor aprendente, colaborativo e reflexivo, observa que os propósitos sumativos de seleção e progressão na carreira geram conflitos que comprometem a dimensão formativa da avaliação e a sua vocação para o desenvolvimento dos professores, ao ponto de porem em causa a transparência e a confiança mútua entre o supervisor / avaliador e o avaliado. Os antagonismos e litígios comprometem o clima de escola.

Mais uma vez, o estudo de um caso real mostra que as práticas das escolas contrariam o quadro teórico apresentado pela literatura da especialidade. A autora fundamenta a sua investigação na análise da grelha de observação utilizada no processo de avaliação, verificando que se trata de uma simples lista de verificação utilizada como instrumento de avaliação sumativa. Por outro lado, a sua participação no processo de ADD permitiulhe constatar que o avaliador e o avaliado se encontram apenas para formalizar a entrega das planificações das aulas a observar e o único momento de negociação teve como objeto a sua calendarização. As etapas definidas para a observação, - antes, durante e depois -,caíram no esquecimento.

O quadro teórico que conceptualiza e estrutura a ADD ficou completamente ignorado ou subvertido. Também aqui a dimensão formativa que sustenta uma supervisão de qualidade e o desenvolvimento profissional dos docentes foi sacrificada por uma lógica sumativa e de prestação de contas burocrática, centralista e imposta. O sentimento que fica nos docentes é o de desperdício de meios e energias.

\section{Maria Deolinda Silva, "A importância da observação de aulas no processo de avaliação de desempenho docente: conceções de professores" \\ Deolinda Silva põe o focus na observação de aulas, mas situa-a no âmbito da ADD e esta na dimensão mais ampla da supervisão pedagógica quando afirma, citando Alarcão e Tavares (2003), que supervisão é, fundamentalmente, interagir, informar, questionar, sugerir, encorajar e avaliar. Parece ficar clara a conceção da autora sobre a ADD e as orientações a seguir na observação de aulas. Vale a pena seguir o aprofundamento teórico em torno destes três campos, bem fundamentado na literatura da especialidade. Começa por apresentar uma perspetiva histórica da}


profissionalização dos professores, um processo que não considera linear nem unidirecional, alternando períodos de profissionalização e desprofissionalização, num percurso repleto de lutas e de conflitos, de hesitações e de recuos.

É neste contexto evolutivo que analisa a avaliação de desempenho docente, que considera como um instrumento de desenvolvimento pessoal e profissional que conduz à melhoria individual das suas práticas de ensino. Para isso importa definir claramente os seus objetivos e funções e as lógicas que regulam a sua implementação, nem sempre perfeitamente claras e conciliáveis. E aqui questiona-se: Para quê avaliar os docentes? -, o que lhe permite desenvolver a dupla dimensão da ADD, uma voltada para a motivação e melhoria profissional dos professores, a outra orientada para a progressão e promoção na carreira. Por fim aprofunda o tema da observação de aulas, que descreve com minúcia com base na literatura especializada.

$\mathrm{Na}$ componente empírica apresenta a opinião de alguns professores sobre o atual modelo da ADD, os seus pontos fortes e a importância da observação de aulas neste processo de Avaliação.

Conclui que a avaliação deve ser realizada e analisada por uma equipa especializada, que a observação de aulas deverá constituir um processo colaborativo entre o professor e o mentor ou supervisor, cabendo a cada um o desempenho de papéis importantes - antes, durante e após a observação. Destaca ainda o facto de os professores referirem que a formação especializada em supervisão pedagógica e avaliação de desempenho docente é o mais urgente neste momento. 